\title{
EDITORIAL
}

\section{Airway clearance techniques in cystic fibrosis}

\author{
A.H. Kendrick
}

C ystic fibrosis (CF) is characterised by the retention of sputum, reduced exercise capacity and breathlessness [1]. To overcome the major problem of sputum retention, a variety of airway clearance techniques have been developed [2,3], all of which have a clear goal: to reduce disease progression by augmenting the normal mucociliary clearance mechanisms and to facilitate expectoration.

The range of techniques available has been summarised in a recent evidenced-based review [4]. What is important about all of these therapies is that they need to have a justifiable reason for their inclusion in the highly demanding care packages that are required by $\mathrm{CF}$ patients.

To date, there is little evidence to suggest that any one intervention is better than another; the only clear conclusion is that there may be some short-term benefit to airway clearance compared to no airway clearance [5]. Both positive expiratory pressure (PEP) [6] and conventional chest physiotherapy [7] are as effective as other forms of airway clearance.

Whilst the trials quoted in the Cochrane reviews [5-7] provide various degrees of quality of evidence, the key information that is missing from these studies is an understanding of the physiological principles by which these different techniques work. Physiologically, the techniques need to do the following. 1) Increase absolute peak expiratory flow (PEF) to move secretions towards the oropharynx. 2) Use two-phase gasliquid flow, both in closed and open airways. In the latter, mucus transport can be achieved by expiratory airflow during forced expiration, as well as tidal breathing. The peak expiratory flow/peak inspiratory flow ratio (PEF/PIF) needs to be $>1.1$ to achieve this $[8,9]$ and the frequency of oscillation needs to be $3-17 \mathrm{~Hz}$, with the ideal frequency being around $13 \mathrm{~Hz} .3)$ Decrease mucus visco-elasticity in the airway, and hence improve mucus transport [10]. 4) Elicite spontaneous coughs by mechanical stimulation of the airways to remove mucus from the trachea, inner and intermediate regions of the lungs [11, 12]. 5) And finally, to increase expectorated mucus volume [13]. However, what all of these are dependent upon is the mechanical properties of the lungs of CF patients, which may deteriorate with disease progression [14, 15]. This might mean alternative approaches have to be adopted.

What is perhaps surprising is that despite our knowledge of what happens when we use these various interventions to aid mucus secretion, such as Flutter ${ }^{\circledR}$ devices and positive expiratory devices (PEP etc.), there have been no published

CORRESPONDENCE: A.H. Kendrick: Dept of Respiratory Medicine, Bristol Royal Infirmary, Bristol, BS2 8HW, UK. Fax: 44 1179286289. E-mail: adrian.kendrick@ubht.swest.nhs.uk studies on the physiological mechanisms of these interventions in CF. In this issue of the European Respiratory Journal, MCCARREN and Alison [16] present the first such study. A total of 18 stable CF patients were subjected to, in randomised order, vibration, percussion, PEP device, Flutter® VRP1 valve and Acapella ${ }_{\circledast}$ PEP. In addition, forced expiratory manoeuvres were voluntary cough and huff from high lung volumes (huffHIGH). The important new measurements, and the reason why this paper is timely, were inspiratory and expiratory flow rates recorded during the manoeuvres and the oscillation frequency determined by frequency spectral analysis. All interventions were performed at the same testing session, which may have had an adverse affect on the results, although there was no increased fatigue noted and tests were performed in a randomised order to avoid order effects.

The key findings of this study were as follows. 1) The PEF of vibration $\left(1.58 \pm 0.73 \mathrm{~L} \cdot \mathrm{s}^{-1}\right)$ was greater by 1.4 (Flutter $1.13 \pm$ $0.3 \mathrm{~L} \cdot \mathrm{s}^{-1}$ ) to 3.6 times (PEP: $0.44 \pm 0.15 \mathrm{~L} \cdot \mathrm{s}^{-1}$ ), but cough PEF was $4.67 \pm 1.19 \mathrm{~L} \cdot \mathrm{s}^{-1}$ and huffHIGH PEF was $5.04 \pm 2.3 \mathrm{~L} \cdot \mathrm{s}^{-1} .2$ ) The frequency of oscillation ranged $6.5-18.3 \mathrm{~Hz}$, with Flutter and Acapella having the higher oscillation frequencies.

What may be ideal in dealing with the problem of mucus secretion is a combination of a high PEF, a high PEF/PIF ratio and oscillation frequencies between $11 \mathrm{~Hz}$ and $15 \mathrm{~Hz}$ [17]. Unfortunately, none of the interventions achieved the ideal combination. Vibration did achieve the critical PEF/PIF of $>1.1$ but fell short of the critical optimal frequency $(8.4 \mathrm{~Hz})$. The Flutter ${ }^{\circ}$ and Acapella ${ }^{\circledR}$ devices were both close to the optimal frequency and within the range of the natural frequency of the cilia beat (11-15 Hz), but were either below (Acapella ${ }_{\circledR}$ ) or around (Flutter ${ }^{\circledR}$ ) the critical PEF/PIF ratio. PEF, however, was low and if PEF itself is important it will be reduced due to the added resistance presented to expiration. All may not be lost though, as the added resistance may result in stabilisation of collapsible airways and allow collateral ventilation to occur, resulting in an increase in gas volume behind the mucus and hence aiding the movement of the secretions $[18,19]$. As with the devices assessed, cough and huffHIGH do not achieve the ideal intervention status, as they do not oscillate airflow, increasing cilia beat frequency and/or decreasing mucus viscosity.

The data presented by MCCARREN and Alison [16] takes us so far but may open up many more questions than it answers. Further studies are needed that use the different devices and compare and contrast the known physiological characteristics of each intervention so that we: 1) know how the devices move mucus; 2) gain a clearer understanding of the volume of mucus produced; 3 ) are aware of the change in spirometric function 
before and after the intervention; and, importantly, 4) gain an insight into patient preference and adherence to therapy. Furthermore, if the purpose of these interventions is to remove secretions from the peripheral airways, then measurement of peripheral airflow or peripheral airway function is required.

So, where does this new data leave us? Well, for the first time we are beginning to have a better understanding of how these interventions work and the advantages and disadvantages of each in relation to mucus removal in patients with cystic fibrosis. Using the ideal criteria of a high peak expiratory flow, a high peak expiratory flow / peak inspiratory flow ratio and an oscillatory frequency of 11-15 Hz, MCCARREN and ALISON [16] suggest that in routine practice cough and huff from high lung volumes should be used, followed by vibration, especially if the patient is fatigued. They also argue that in the absence of a carer, the Flutter ${ }^{\circledR}$ device appears to be the intervention of choice. None are perfect and the inferences from the data presented by MCCARREN and ALISON [16] are the best compromise that can be achieved with current interventions. The challenge now is to refine the interventions to fulfil the criteria whilst at the same time allowing patients to take more control of management.

\section{REFERENCES}

1 Yankaskas JR, Marshall BC, Sufian B, Simon RH, Rodman D. Cystic fibrosis adult care. Consensus conference report. Chest 2004; 125: Suppl. 1, 1s-39s.

2 Association of Chartered Physiotherapists in Cystic Fibrosis. Clinical Guidelines for the Physiotherapy Management of Cystic Fibrosis. Kent, Cystic Fibrosis Trust, 2003.

3 Hess DR. The evidence for secretion clearance techniques. Respir Care 2001; 46: 1276-1293.

4 Bradley JM, Moran FM, Elborn JS. Evidence for physical therapies (airway clearance and physical training) in cystic fibrosis: an overview of the five Cochrane systematic reviews. Respir Med 2006; 100: 191-201.

5 van der Schans C., Prasad A., Main E. Chest physiotherapy compared to no chest physiotherapy for cystic fibrosis. In: The Cochrane Library, Issue 2. Chichester, Wiley, 2000.
6 Elkins MR., Jones A., van der Schans C. Positive expiratory pressure physiotherapy for airway clearance in people with cystic fibrosis. In: The Cochrane Library, Issue 1. Chichester, Wiley, 2004.

7 Main E., Prasad A., van der Schans C. Conventional chest physiotherapy compared to other airway clearance techniques for cystic fibrosis. In: The Cochrane Library, Issue 1. Chichester, Wiley, 2005.

$8 \mathrm{Kim}$ CS, Rodriguez CR, Eldridge MA, Sackner MA. Criteria for mucus transport in the airways by two-phase gas-liquid flow mechanism. J Appl Physiol 1986; 60: 901-907.

9 Kim CS, Iglesias AJ, Sackner MA. Mucus clearance by twophase gas-liquid flow mechanism: asymmetric periodic flow model. J Appl Physiol 1987; 62: 959-971.

10 App EA, Kieselmann R, Reinhardt D, et al. Sputum rheology changes in cystic fibrosis lung disease following two different types of physiotherapy. Chest 1998; 114: 171-177.

11 Hasani A, Pavia D, Agnew JE, Clarke SW. Regional lung clearance during cough and forced expiration technique (FET): effects of flow and visco-elasticity. Thorax 1994; 49: 557-561.

12 Scherer PW. Mucus transport by cough. Chest 1981; 80: 830-833.

13 Konstan MW, Stern RC, Doershuk CF. Efficacy of the Flutter device for airway mucus clearance in patients with cystic fibrosis. J Pediatr 1994; 124: 689-693.

14 Arora NS, Gal TJ. Cough dynamics during progressive expiratory muscle weakness in healthy curanized subjects. J Appl Physiol 1981; 51: 494-498.

15 van der Schans CP. Forced expiratory manoeuvres to increase transport of the bronchial mucus: a mechanistic approach. Monaldi Arch Chest Dis 1997; 52: 367-370.

16 McCarren B, Alison JA. Physiological effects of vibration in subjects with cystic fibrosis. Eur Respir J 2006; 27: 1204-1209.

17 Gross D, Zidulka A, O’Brien C, et al. Peripheral mucociliary clearance with high frequency chest wall compression. J Appl Physiol 1985; 58: 1157-1163.

18 Fink JB. Positive pressure techniques for airway clearance. Respir Care 2002; 47: 786-796.

19 Delaunois L. Anatomy and physiology of collateral respiratory airways. Eur Respir J 1989; 2: 893-904. 